\title{
Effects of Tailored and ACT-Influenced Internet- Based CBT for Eating Disorders and the Relation Between Knowledge Acquisition and Outcome: A Randomized Controlled Trial
}

Sandra Weineland, Ata Ghaderi, Hedvig Andersson, Nicole Parmskog, Emelie Hjort, Anna Svanberg Wärn, Maria J annert and Gerhard Andersson

The self-archived version of this journal article is available at Linköping University Institutional Repository (DiVA):

http:/ / urn.kb.se/ resolve?urn=urn:nbn:se:liu:diva-139900

N.B.: When citing this work, cite the original publication.

Weineland, S., Ghaderi, A., Andersson, H., Parmskog, N., Hjort, E., Svanberg Wärn, A., J annert, M., Andersson, G., (2017), Effects of Tailored and ACT-Influenced Internet-Based CBT for Eating Disorders and the Relation Between Knowledge Acquisition and Outcome: A Randomized Controlled Trial, Behavior Therapy, 48(5), 624-637. https:// doi.org/ 10.1016/j.beth.2017.02.002

Original publication available at:

https:// doi.org/ 10.1016/j.beth.2017.02.002

Copyright: Elsevier

http:// www.elsevier.com/

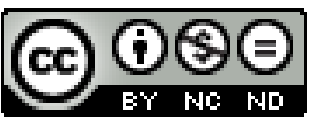




\section{Effects of Tailored and ACT-Influenced Internet-based CBT for Eat- ing Disorders and the Relation between Knowledge Acquisition and Outcome: a Randomized Controlled Trial}

Sandra Weineland Strandskov ${ }^{12}$, Ata Ghaderi ${ }^{3}$,Hedvig Andersson ${ }^{1}$, Nicole Parmskog ${ }^{1}$, Emelie Hjort $^{1}$, Anna Svanberg Wärn ${ }^{1}$, Maria Jannert ${ }^{1}$, Gerhard Andersson ${ }^{1}$

${ }^{1}$ Linköping University Department of Behavioural Sciences and Learning (IBL), SE-58183 Linköping, Sweden, 2Närhälsan, Research and Development Center, Primary Health Care, Södra Älsvborg, Borås, Sweden, ${ }^{3}$ Karolinska Institutet, Department of Clinical Neuroscience (CNS), Division of Psychology, , SE-17177 Stockholm, Sweden

Corresponding author: Sandra Weineland, sandra.weineland@vgregion.se, sandra.weineland@liu.se. Department of Behavioural Sciences and Learning (IBL), SE-581 83 Link581 83 LinkBL 


\begin{abstract}
Objectives: This is the first trial to investigate the outcome of tailored and ACT-influenced, cognitive behavioral Internet treatment for eating disorder psychopathology, and the relation between knowledge acquisition and outcome.
\end{abstract}

Design: Randomized controlled design, with computer-based allocation to treatment or waiting list control group.

Participants: Participants were recruited via advertisements in social media and newspapers in Sweden. Participants fulfilling the criteria for bulimia nervosa (BN), or Eating Disorder Not Otherwise Specified (EDNOS), with a BMI above 17.5, were enrolled in the study ( $\mathrm{N}=$ 92).

Intervention: The treatment group received an Internet-based, ACT-influenced CBT intervention, developed by the authors, for eating disorders. The treatment lasted eight weeks, and was adapted to the participant's individual needs. A clinician provided support.

Main outcome measures: Eating disorder symptoms and body shape dissatisfaction.

Results: Intent-to-treat analysis showed that the treatment group $(n=46)$ improved significantly on eating disorder symptoms and body dissatisfaction, compared with the waiting list control group $(\mathrm{n}=46)$, with small to moderate effect sizes (between group effects, $d=0.35$ 0.64). More than a third of the participants in the treatment group (36.6\%), compared to $7.1 \%$ in the waiting list control condition, made clinically significant improvements. Results showed a significant increase in knowledge in the treatment group compared to the waiting list control group (between group effect, $d=1.12$ ), but we found no significant correlations between knowledge acquisition and outcome $(r=-0.27$ to $-r=0.23)$. 
Conclusion: The results provide preliminary support for Internet based, tailored, and ACTinfluenced treatment, based on CBT for participants with eating disorder psychopathology.

Trial registration: Clinical Trials NCT02700620. 


\section{Introduction}

Cognitive behavioral therapy (CBT) is the treatment of choice for bulimia nervosa (BN) and binge eating disorder (Wilson, Grilo, Witousek, 2007). In the study by Fairburn, and colleagues (2009), the remission rate among participants with BN, or Eating Disorder Not Otherwise Specified (EDNOS), receiving the enhanced version of CBT (i.e. CBT-E) was $66 \%$. Watson et al., (2012) reported a within-group effect that was large to moderate on eating disorder symptoms, and clinically significant improvement for $36 \%$ of patients diagnosed with EDNOS and 50 \% of patients diagnosed with BN, receiving CBT-E. CBT-E stands for an enhanced, personalized, "transdiagnostic" treatment for eating disorders, which includes strategies for involving and retaining patients, achieving early change and stabilizing healthy eating patterns, addressing over-evaluation of shape and weight, and identifying and addressing other important maintaining variables, such as mood intolerance, clinical perfectionism, core low self-esteem, and marked interpersonal difficulties (Fairburn, 2008).

Most people in need of psychological treatment do not receive it (Kazdin, 2008). There is a lack of implementation of evidence-based treatments for BN, and EDNOS, among clinicians in community settings (Wallace \& van Ranson, 2011). Internet-based CBT may be an efficient strategy for reaching more people in need of treatment for eating disorder psychopathology. Internet-based mental health interventions provide a special opportunity for extending mental health interventions (Kazdin, 2008). Using web-based CBT treatment with therapist support is a well-established treatment format for a range of conditions (Andersson, 2016). The efficacy of Internet-based guided self-help for bulimia nervosa and binge eating disorder has been investigated in several studies (Aardoom et al., 2013; Loucas et al., 2014; Melioli, et al., 2016; Schlegl, Bürger, Schmidt, Herbst \& Voderholzer, 2015). 
A recent multicenter randomized non-inferiority trial showed that an Internetbased CBT group therapy conducted via a therapeutic chat group was mostly not inferior to individual face-to-face CBT at the 12 months follow-up (Zerwas et al., 2017), although the group condition was inferior to the face-to-face condition in terms of abstinence from binge eating and purging at post-treatment. Loucas et al. (2014) found only small effects in their review of Internet-based treatments for BN and EDNOS, and conclude that more research is needed to clarify possible effects of CBT via Internet for this group of patients. Further, Loucas et al. (2014) highlight that Internet-delivered CBT for this group of patients should be personalized. Adapting treatment to individual needs in Internet-based CBT has been successfully implemented for conditions other than eating disorders by including additional modules for comorbid conditions (Berger, Boettcher \& Caspar, 2014; Bergman Nordgren et al., 2014; Johansson, Sjöberg, Sjögren et al., 2012). In the first study of CBT-E, Fairburn and colleagues (2009) compared two versions of CBT-E; one only focusing on core symptomatology of ED (focused), and another addressing additional maintaining factors (broad). Hence, in CBT-E treatment was personalized and tailored to the individual. Results showed that participants exhibited substantial and equivalent change, which remained at the follow-up. Participants with eating psychopathology complicated by mood intolerance, clinical perfectionism, low self-esteem, or interpersonal difficulties, appeared to respond better to the more personalized treatment of CBT-E. Ghaderi (2006) compared manual-based CBT with CBT based on functional analysis (as a method of individualization) for participants with BN, and showed preliminary support for a higher level of individualization in terms of response to treatment. Treatment can also be individualized by declaring one's own personal values with the aim of motivating behavioral change in Acceptance and Commitment Therapy (ACT) (Hayes, Stroshal \& Wilson, 1999). Since lack of motivation and high ambivalence are major obstacles for efficient treatment of eating disorders, this component of ACT might make a contribution to 
increased efficacy of CBT for ED. Similarly, acceptance strategies from ACT might help alleviate cognitive obstacles that for some of the patients are difficult to overcome with currently used strategies such as restructuring or meta-cognitive awareness. Ljótsson et al. (2007) found that CBT-based guided self-help influenced by ACT for patients with BN and binge eating was effective, with moderate to large reductions in several eating disorder-specific parameters.

For the purposes of the present study, we developed an ACT-influenced, cognitive behavioral, Internet-based treatment, consisting of modules allowing treatment adjustment to the needs of each patient. Treatment goals are to establish healthy and regular eating, focus on maintaining variables, and address other psychological problems that increase the risk of relapse or poor outcome. The treatment was developed with inspiration from Fairburn’s transdiagnostic model for eating disorders (Fairburn, 2009), and literature on ACT for eating disorders (Forman, Lillis, Butryn \& Haynos, 2016). Psychoeducation for eating disorders and anxiety was considered an important part of the treatment model. Beyond common CBT-E strategies, the current treatment manual incorporates strategies drawn from ACT. For example, body checking and avoidance are addressed through both exposure and acceptance exercises, aimed to reduce over-evaluation of shape and weight. Declaring own personal values is included, aimed at developing healthy activities in life, such as caring for the body.

Clinical research should seek to uncover mechanisms of psychological treatments (Holmes, Craske, Graybiel, 2014). Since CBT in general, and Internet-based CBT in particular, involve psychoeducation, it seems important to investigate the role of knowledge acquisition in treatment outcomes. Generally, the purpose of psychoeducation is to increase participants' knowledge of the problems and treatment process. It can per se be considered a cognitive intervention. However, there are indications that clients often misinterpret psychoeducation (Sanderson \& Bruce, 2007), and forget much of the information provided (Har- 
vey et al., 2014). There are only a few trials in which the relation between knowledge acquisition and treatment outcome has been evaluated. In a review study, increased knowledge of depression was associated with improved psychosocial functioning and treatment adherence among depressive patients undergoing CBT treatment (Tursi, Baes, Camacho, Tofoli \& Juruena, 2013). Davis, Olmsted and Rockert (1997) compared a brief group treatment, designed to be purely educational, with longer CBT therapy for participants with bulimia nervosa (BN). Both treatments seemed to be equally effective for the healthiest participants, suggesting the effectiveness of psychoeducation (Davis, Olmsted, Rockert, Marques \& Dolhanty, 1997). In a study by Tatham, Dodd \& Waller (2015) the impact of a four-hour session pre-treatment psychoeducational intervention on outpatients with diagnoses of full or atypical anorexia nervosa or bulimia nervosa was evaluated. Results showed reduced unhealthy eating attitudes among bulimic patients, regardless of initial levels of eating and personality pathology. In contrast, psychoeducation was not effective for anorexia nervosa sufferers (Tatham, Dodd \& Waller, 2015). Psychoeducation is a well-integrated part of treatments for eating disorder patients. It appears important to explore the role of psychoeducation in the treatment of eating disorders. To the authors' knowledge there is no published study of the relationship between psychoeducation and outcomes of Internet-based CBT for patients with eating disorders.

The first aim of the current study was to investigate the effects of tailored and ACT-influenced, Internet-based, cognitive behavioral therapy for participants with BN and EDNOS. The second aim was to investigate the change in participant knowledge and the relationship between psychoeducation and treatment outcome. The following two hypotheses were tested: 1) Individualized, ACT-influenced, Internet-based, cognitive behavioral therapy for patients with BN and EDNOS is effective in reducing symptom of eating disorder, depression and anxiety, and in increasing quality of life. 2) There is a significant association between the change in participants' knowledge and the change in outcomes across the treatment. 


\section{Method}

\section{Participants and recruitment}

The study was approved by the Ethical Review Board in Linköping (Dnr. 2014/426/31). The trial was registered at https://clinicaltrials.gov/ in the last author's name. Informed consent was obtained from all participants after providing detailed information about the study, and providing them an opportunity for questions.

Participants were recruited via advertisements in the social media and Swedish newspapers. They signed up via the treatment study website (www.zenitstudien.se), and were enrolled in the study through an Internet-based, secure platform for the study. An informed consent form was signed by participants and sent back to the research group via regular mail.

Screening and pre measures were taken from 2015-01-12 to 2015-01-22. A total of 183 people registered their interest, upon which they were asked to electronically respond to the screening form (see Figure 1). It was decided to stop recruitment at this time, as the power analysis had shown that the number of participants were large enough to detect differences between groups.

Figure 1 - Flow of the study

The inclusion criteria for the study were that participants were at least 18 years old, could speak and understand Swedish, and met the criteria for BN or EDNOS. The following exclusion criteria were used: (a) diagnosis of anorexia nervosa within the last two years, (b) BMI of 17.5 or below, (c) concurrent psychological treatment, or (d) acute risk of suicidality as determined by a clinician experienced in psychiatric disorders and eating disorder psychopathology. A total of 17 people did not meet the inclusion criteria, or could not be reached after completing the online screening forms. Five of the 17 (29.4\%) who underwent screening 
were excluded due to the diagnosis of anorexia nervosa. None were excluded due to suicidality. A total of 29 people were excluded after the diagnostic interview. Ten declined participation (34.4\%), two (6.9\%) could not commence treatment on time, and 17 (58.6\%) received other treatments, met criteria for AN, not detected during the screeening, were in need of more comprehensive care, or were pregnant. The external loss of potential participants was 46 (33.3\%). Those fulfilling the study's inclusion criteria assessed with online screening forms were then interviewed by phone using the Mini International Neuropsychiatric Interview (MINI) (Sheehan et al., 1998). MINI interviews were conducted by four supervised clinical psychology master’s students (the same students that delivered the treatment to participants). They had previous clinical training in conducting the MINI, and thus no inter-rater reliability was conducted for the current study. Those who fulfilled the DSM-IV (American Psychiatric Association, 2000) criteria for EDNOS or BN based on an interview with the MINI, were invited to participate. A total of 92 individuals were finally enrolled in the study. Participants were randomized into one of two groups: the treatment or waiting list control group. Randomization was performed by an independent researcher not included in the research group, using the website www.randomizer.org, which is a computer-based generator that uses a complex algorithm for randomizing participants to experimental conditions. The independent researcher was given a list of the included participants and then she randomized them via the website to either treatment or control group.

The treatment group received treatment immediately, while the wait list control group received treatment first after the treatment group had completed treatment, and both groups were re-assessed. Thus, all participants received treatment, but at different time intervals. Measures were obtained pre and post treatment. Our sample $(\mathrm{N}=92)$ included 89 women (97\%), and 3 men. The mean age was 29, and BMI averaged 25. Forty-five participants (49\%) 
had received previous psychological treatment for eating disorders. See Table 1 for characteristics of the study sample.

Table 1 - Characteristics of the study sample, and wait list control group versus the treatment group

As seen in Table 2, participants had, on average, a history of eating disorders for an average of 13 years. The first diet attempt started on average at 16 years of age. See Table 2 for clinical characteristics.

Table 2 - Clinical characteristics of the total sample, as well as wait list control group versus the treatment group

Thirty-six participants (39 \%) fulfilled the diagnostic criteria for BN. The majority of participants (61 \%) fulfilled the criteria for EDNOS. A total of 21 participants (77 \%) had a comorbid psychiatric diagnosis. As seen in Table 3, a large proportion of the participants fulfilled the criteria for generalized anxiety disorder (GAD).

Table 3 - Diagnostic participant status

Fifteen participants in the treatment group discontinued treatment prematurely, thus $32.6 \%$ of the treatment group dropped out of treatment. Four participants in the wait list control group (8.7\%) dropped out. Altogether 19 participants dropped out of treatment during treatment and wait list control group. One participant did not fill in the post assessment, which means that data were missing for 20 participants. The internal drop out rate was $21.7 \%$.

\section{Treatment}

The treatment was conducted from 2015-02-09 to 2015-04-05. Participants received Internetbased and ACT-influenced CBT for eating disorders developed by the authors. The treatment 
protocol was influenced by Fairburns transdiagnostic CBT treatment for eating disorders (Fairburn, 2008) and ACT manuals for eating disorders (Forman, Lillis, Butryn, Haynos, 2016; Ljótsson et al., 2007; Lillis, Dahl \& Weineland, 2014). Psychoeducation included information on maintaining factors for eating disorder behavior, the rationale for daily monitoring of eating and establishing regular eating, dietary restraint, dietary rules, exposure to avoided stimuli and situations, as well as addressing body image concerns. The ACTinfluenced parts of the treatment included skills for willingness, mindfulness in eating, and in general, remaining detached to distressing thoughts concerning the body and eating (defusion), as well as values work (e.g., importance of healthy eating). Participants had the opportunity to interact with facilitators via feedback on written exercises and messages. The material was created as interactive, which allowed immediate feedback on exercises if requested, and individualization of treatment. Participants were contacted mainly via the website. They could also ask questions about the exercises, or other questions related to treatment and problems. Therapists were online daily providing immediate feedback through written messages via the website. In some cases participants were contacted by telephone for a detailed description of the treatment. The phone calls focused on supporting participants in completing exercises and understanding different aspects of the treatment. Four participants in the treatment group (8.7\%) received one to five calls each. Treatment length was eight weeks, and the treatment program consisted of eight modules (Table 4). The decision for which module to choose was made jointly by participants and therapists. For a detailed description of treatment modules, see table 4.

Table 4 - Treatment modules

All participants were assigned a therapist who followed them throughout treatment. Four supervised clinical psychology master's students guided the treatment. They received weekly supervision from clinically experienced supervisors. To secure participant 
safety, weekly measures for suicidality and eating disorder behavior were taken. Worsening of eating disorder or depressive psychopathology during the course of treatment was addressed by means of calling participants for a checkup. Telephone contact was then individually tailored, and focused on, for example, strategies for handling strong negative emotions, behavior activation, and helping participants use health promoting behavior. If the suicide risk was assessed as high, the participant would be referred to their local psychiatric emergency unit. There was a weekly assessment by the Patient Health Questionnaire (PHQ-9), from which question 9 was used to assess suicide risk. Therapists contacted participants declaring having such thoughts daily. This applied to all participants, in both control and treatment groups. Five participants were contacted, and a stepwise interview assessing the seriousness of suicidal ideation was used. This study assessed no participants with a high suicide risk needing referral to psychiatric care. Assistance from therapists to participants consisted of short feedback on homework, reminders, and support. Overall, the therapists used roughly 15 minutes weekly providing participants with feedback, support, and responses to emails.

\section{Measures}

Screening and pre measures were taken from 2015-01-12 to 2015-01-22. Post measures were taken immediately after the intervention.

\section{Interview.}

Mini International Neuropsychiatric Interview (M.I.N.I.) is a structured diagnostic interview developed jointly by psychiatrists and clinician. MINI has an administration time of approximately 15 minutes (Sheehan et al., 1998). The psychometric properties show very good test-retest reliability, with 14 of the 23 of the diagnoses above a kappa value of .75 and excellent inter-rater-reliability with all of the diagnoses above .75 . Validity show good results for most of the diagnoses psychopathology, with kappa values of .49-.59, except for the more severe psychopathology, .11-.30 (Sheehan et al., 1998). 


\section{Primary outcomes.}

The Eating Disorders Examination Questionnaire (EDE-Q) is a questionnaire measuring eating disorder symptoms (Fairburn \& Beglin, 2008) based on the Eating Disorders Examination interview (EDE) (Fairburn \& Cooper, 1993). The EDE-Q has good psychometric properties, and good validity and reliability (Fairburn \& Beglin, 2008; present study alpha $=0.88$ ). The instrument consists of 28 questions, and examines the core psychopathology of eating disorders during the last 28 days. EDE-Q comprises four subscales and a global score. The four subscales are eating concerns (present study alpha $=0.71$ ), shape concerns (present study alpha $=0.83$ ), weight concerns (present study alpha $=0.67)$, and restraint (present study alpha $=$ 0.76) (Fairburn \& Beglin, 2008). Welch, Lagerström and Ghaderi (2012) developed a brief, 8item version of the Body Shape Questionnaire (BSQ-8C) based on the full version (Cooper , Taylor, Cooper \& Fairburn, 1987) to investigate body shape dissatisfaction. The BSQ-8C has shown good psychometric properties, with high test-retest reliability and high validity (Welch et al., 2012 present study alpha $=0.85$ ).

\section{Secondary outcomes.}

The Patient Health Questionnaire (PHQ-9) is a self-assessment questionnaire consisting of nine items, used to screen for depression (Kroenke, Spitzer \& Williams, 2001). The PHQ-9 is a reliable and valid measure for depression severity (Hansson, Chotai, Nordström \& Bodlund, 2009; present study alpha $=0.75$ ). The questionnaire scores each of the nine DSM-IV criteria (Kroenke, Spitzer \& Williams, 2001). Generalized Anxiety Disorder 7-item scale (GAD-7) is a questionnaire designed to measure anxiety symptoms (Spitzer, Kroenke, Williams \& Lowe, 2006). The questionnaire includes seven statements, which are based on diagnostic criteria for a generalized anxiety disorder (GAD; APA, 2000). The instrument has good psychometric properties, with high internal consistency and test-retest reliability (Spitzer et al., 2006; pre- 
sent study alpha $=0.87)$. The Quality of Life Inventory $(Q O L I)$ is a questionnaire designed to measure the subjective quality of life (Frisch, Cornell, Villaneva \& Retzlatt, 1992). It contains items for 16 areas of life where individuals report their subjective experience of importance and satisfaction. The instrument has good psychometric properties with high internal consistency, and good test-retest reliability (Frisch et al., 1992; present study alpha $=0.79$ ).

\section{Knowledge acquisition test.}

We designed a test to investigate to what extent the participants had acquired knowledge on eating disorders during the treatment phase. The test measured knowledge on eating disorder psychopathology and its treatment. The test construction involved selection of test items, consulting experts in the field of eating disorders, and piloting the test with psychology students $(n=32)$. The knowledge test emanated mainly from psychoeducation from the first four modules. The final test consisted of 16 questions with three possible answers, and included a rating of respondent certainty for their answers, using a four-point scale from "not at all certain" to “very certain”. The knowledge test was scored in two ways. First, a total score based on the total number of correct answers was calculated. Second, a weighted total score in which certainty of answers were factored was calculated. This meant a higher score if you were correct and certain, a lower score if you were correct, yet uncertain, and finally, a negative score if you were wrong but certain. Reliability analyses of internal consistency, measured with Cronbachs' alpha, was $\alpha=0.62$. The questionnaire can be assessed by contacting the corresponding author.

\section{Statistical analysis}


The Statistical Package for the Social Sciences, version 22.0 (SPSS 22) was used for the statistical analyses. ANCOVA was used to investigate group differences ${ }^{1}$. Within-group differences were calculated using dependent samples t-tests. Cohen’s d was used for calculating effect sizes (Cohen, 1988). Missing values were replaced by multiple imputations as implemented in SPSS. To assess clinically significant change, a 2-step approach was used according to Jacobson and Truax (1991). The first step was to calculate a Reliable Change Index (RCI), and the second involved setting a limit marking movement from a "dysfunctional population" to a "functional population". The RCI (created to determine the change in the outcome measure over and above errors related to the reliability of the measures) is considered significant when the RCI is greater than 1.96, indicating that the probability of change being due to chance is less than 0.05 . The second step used to assess clinically significant change was to employ an established criterion for remission (Fairburn, 2009), defined as a posttreatment EDE-Q score within one standard deviation of the mean of the general Swedish population (Welch et al., 2011). The knowledge test was administered before and after the intervention. An analysis of covariance (ANCOVA) was performed to examine the difference between the treatment and waiting list control groups regarding change in score from pre to post on the knowledge test. The pre measurement was used as a covariate. Pearson's product moment correlation was used to investigate the association between changes in the level of knowledge from pre to post, and change scores from pre to post on the various outcome measures.

\section{Results}

\section{Pre testning}

\footnotetext{
${ }^{1}$ At the suggestion of reviewers, we also provide a summary of outcomes when analysed with repeated measures ANOVA. Please see online supplementary material.
} 
To compare treatment and control groups in terms of symptoms and demographic variables for pre treatment measures, the independent t-test and $\chi^{2}$ test were conducted. No significant differences, were identified between treatment and control groups.

\section{Treatment adherence}

A total of 19 (21.7\%) participants dropped out after randomization. The dropout rate was markedly higher in the treatment group (32.6\%) compared to the control group (8.7\%). Those discontinuing treatment prematurely did not differ from those who completed treatment for any of the demographic variables or symptom estimates, with the exception of the frequency of agoraphobia. Dropouts from the treatment group had greater than expected agoraphobia, $\chi^{2}$ $=(1, \mathrm{~N}=92)=5.9, p=0.04$.

\section{Treatment outcome}

\section{Intent-to-treat analysis.}

As shown in Table 5, we found significant group differences at post-treatment for the primary outcomes for eating disorder psychopathology measured with the EDE-Q and body dissatisfaction, measured by the BSQ, after controlling for corresponding pre-treatment values. See Table 5 for primary and secondary outcomes. We also did the analyses using repeated measure ANOVA. The outcome is presented in the online supplementary material (Table 6) showing the same pattern as the ANCOVA in terms of significant interaction effects for the EDEQ global score and its subscales, and the BSQ, while no significant interaction effects were found for the rest of the outcome variables (SWLS, QOLI, GAD-7, and PHQ-9). Rate of abstinence defined in terms of no binge eating episodes at all as reported through the EDE-Q at post treatment was $10.3 \%$. Divided by the BN and EDNOS diagnostic categories, the corresponding figures were $11.8 \%$ and $8.3 \%$. Although the abstinence rate was slightly higher in the BN group, the difference was not significant. 
Table 5 - ITT-analysis

\section{Clinically significant improvement.}

Following the proposed criteria by Jacobson and Truax (1991), 36.6\% in the treatment group, and $7.1 \%$ in the waiting list control group, achieved clinically significant improvement as measured by the EDE-Q. In accordance with the Fairburn et al. (2009) definition of clinically significant improvement and using Swedish norms (Welch et al., 2011), 53.3\% of the treatment group, and $23.8 \%$ of the waiting list control group, reached clinically significant improvement.

\section{The role of knowledge acquisition.}

The results showed a significant effect on groups for the knowledge test, $F(1,70)=24.93, p$ $<.001$. Knowledge increased in the treatment group $(M p r e=12.03(8.64), M$ post $=22.80$ (9.79) compared with the waiting list control group (Mpre=10.12(8.46), $M$ post $=11.43$ (10.50), with a large between group effect $(d=1.12)$. The Pearson product moment correlation was used to investigate the association between changes in the level of knowledge and change scores for the various treatment outcome measures. There was no significant correlation between the change in the level of knowledge and the change in scores on any of the outcome measures in the group receiving the treatment $(r=-0.27-.23)$.

\section{Discussion}

The first aim of the current study was to investigate the effects of tailored and ACTinfluenced Internet-based CBT for patients with BN and EDNOS. A within-group change occurred in the treatment group, whereby eating disorder symptoms and body dissatisfaction, measured by the EDE-Q and BSQ, improved significantly. As a diagnostic interview such as the EDE was not used at pre-, and post-treatment, the abstinence rate after the end of the treatment was defined using the reported frequency of binge eating in the EDE-Q. Just above 
$10 \%$ met this criterion for abstinence. However, any figures on self-reported binge eating should be interpreted cautiously. At post treatment, after controlling for baseline severity, the treatment group was significantly improved in comparison to the waiting list control group. Effect sizes were small to moderate $(d=0.35-0.64)$. A mentionable proportion of participants in the treatment group (36.6\%) reached clinically significant improvement. Watson et al., (2012) report a moderate to large within-group effect on the EDE-Q total scale, and a clinically significant improvement (according to Jacobson \& Truax, 1991) for 36\% of patients with EDNOS, which is in line with the present results. In a guided self-help study, Ljótsson et al. (2007) showed that $40 \%$ of the participants reached clinically significant improvement in binge eating episodes. Loucas et al. (2014) found small effects in their review of Internetbased treatments for eating disorders $(n=20)$. The results of the current study show some moderate effects as well, and a fair number of participants recovering from eating disorder symptoms. Both the treatment and waiting list control groups in the current study improved on quality of life, with a small within-group effect, from pre to post assessment. In their review paper, Aardoom et al. (2013) found mixed results for depressive symptomatology in Internet-based CBT for eating disorders. We found no significant between-group differences on depressive symptomatology, as both groups reported improvements corresponding to moderate size effects from pre- to post-treatment. In summary, our results suggest that tailored, ACT-influenced, Internet-based CBT is promising in reducing eating disorder psychopathology among patients with BN and EDNOS.

Aardoom et al. (2013) showed a dropout rate for Internet treatments for eating disorders between $5.3 \%$ and $76.8 \%$. Furthermore, face-to-face contact or contact via mail or telephone, was associated with a lower dropout rate (Aardoom et al., 2013). Dropout analysis in the current study showed no significant difference between groups, except for those who dropped out showing a higher than expected frequency of agoraphobia. This was an unex- 
pected finding, which might simply be a sampling effect. No firm conclusions can be drawn before it has been investigated in other independent studies.

Given the evidence for the benefit of support in web-based treatments (e.g., Loeb et al., 2000), support was included in the current study via text messaging and when needed also via telephone. This treatment lasted only eight weeks, and traditional treatments usually last 20-40 weeks (Carrard et al. 2011). Similar effects despite shorter duration is plausible, as previous research has shown that much of the change in CBT occurs in the early stage of treatment (e.g., Schibbye et al., 2014; Wilson et al., 2002;), and that longer treatment, beyond a certain point, may not yield any further effect.

To our knowledge this is the first published study to evaluate the role of psychoeducation in Internet-based treatment for patients with BN and EDNOS. We investigated the change in knowledge from pre to post treatment, and the relationship between knowledge and treatment outcomes. Knowledge increased among those who completed the treatment in the treatmentgroup, compared with the waiting list control group. This result is in line with previous research on other diagnoses (social anxiety: Andersson et al. 2012: depression: Scogin et al., 1998; Friedberg et al., 1998). The results, however, showed no significant correlations between psychoeducation and treatment outcomes. There are different possible explanations for this. There can be a third factor, or combination of factors, affecting both outcomes and knowledge, for example, practice through homework. It might be that implementing knowledge is more of a key to behavior change than knowledge alone. Bendelin et al. (2011) showed that participants who practiced what they learned in treatment improved significantly, compared with those who only studied psychoeducation with no practical application. Future studies should not only assess the level of knowledge acquisition, but also the extent to which is feel relevant, and applied by the patients during the course of treatment. 
There are some limitations in the current study. The treatment lasted only eight weeks in comparison with traditional treatments, usually lasting about 20 weeks. The results were, however, in line with previous studies with longer treatment interventions (e.g., Aardoom, Dingers, Spinholez \& Furth 2013; Watson et al., 2012). Thus, it is conceivable that early change did take place in this trial, similar to what has been shown in previous trials of CBT for eating disorder s (Wilson, Fairburn Agras, Walsh \& Kraemer, 2002). Participants also had the possibility to review the module several times during the treatment period. The brief duration of the treatment might also be seen as a strength. The dropout rate in the current study was $21.7 \%$, which is similar to previous studies (Grilo \& Masheb 2005; Loeb et al., 2000; Loucas et al., 2014). However, the notable difference in dropout rates between the conditions is an important limitation to keep in mind. Lack of follow-up data is a significant limitation of the study, as long-term maintenance of effects is a clinically important question. Only one of the studies in Loucas et al, (2014) included a follow-up (Sanchez-Ortiz et al., 2011), and, therefore, we encourage long-term follow-up studies to see how symptoms and quality of life changes over time. All post-treatment data are based on self-report measures, which is another limitation of the current study. Objective data based on semi-structured interviews such as the EDE would add to the credibility of the outcome, as some of the symptoms such as the frequency of binge eating are difficult to measure reliably through selfreport. Likewise, lack of inter-rater reliability among those who conducted the MINI interview should also be noted as a limitation. Finally, two other limitations should be mentioned. The first one is the low internal consistency $(\alpha=.62)$ of the knowledge questionnaire, and the second one is the validity of the EDE-Q subscales given the mixed results from studies investigating its psychometric properties. There are some strengths to the study. We aimed to include participants with any eating disorders with the exception of those who were significantly underweight regardless of comorbid problems, age, and duration of ED to increase the gen- 
eralizability of the results. The sample showed significant psychopathology at pretreatment screening, but a substantial portion of the participants did meet the criteria for clinically significant improvement after the intervention, cautiously suggesting that tailored and ACTinfluenced Internet-based CBT might be a promising treatment. If replicated and showing favorable outcome, a clinical implication could be to use guided Internet-delivered treatment as the first step in a stepped-care model for patients with eating disorders, as suggested by Crow et al. (2013).

This was the first study to explore the outcome of tailored and ACT-influenced Internet-based CBT treatment for patients with eating disorders. The treatment was associated with favorable outcomes in eating disorder psychopathology, and a sizeable proportion of participants reached clinically significant improvement. This study preliminarily suggests that web-based psychological treatment for eating disorder-related problems may be promising as an initial intervention. Internet administered treatment could function as a supplement to present health care in a stepwise care model. Future studies should further evaluate web-based psychosocial treatments for ED implemented at clinics in a stepped care model. There are already some good technology-enhanced treatment delivery systems (e.g., Recovery Record, Overcoming Bulimia Online, and Featback) that should be considered in future development of Internet-based interventions for ED. Our intervention has several similarities with these systems, and each system has some unique features, which sets the scene for future comparisons and further developments. We encourage long-term follow-up studies to see how participants progress, and should include both quantitative and qualitative measurements of, for example, experiences of treatment. Since Wilson et al. (2002) suggest that the largest treatment effects are achieved at the beginning of treatment, future studies should further investigate the rate and magnitude of improvement on a continuous manner (session by session) to help pro- 
vide useful information on what would be the most optimal length of treatment, and whether the pattern of early response varies dependent on the level of individualization.

The results also showed that the level of knowledge, as measured by a knowledge test, increased after treatment, but the change in knowledge level was not related to the outcome of treatment. Future research should further investigate the relationship between different types of knowledge, such as knowledge of symptoms, treatment and coping strategies, and treatment outcomes. This would provide useful information about whether psychoeducation in psychotherapy should focus more on a specific type of knowledge. Another research question for future studies is the extent to which learned skills are practiced by participants, and their relationship to outcomes. Investigating whether psychoeducation might lead to a shift in perception of experienced problems, and/or psychological flexibility, which in turn may be associated with improvements.

\section{Acknowledgements}

We thank George Vlasceu, the webmaster for the trial. A Linköping University professorial grant to the last author funded the study.

\section{Conflict of Interest Statement}

The authors declare no conflict of interest.

\section{References}

Aardoom, J. J., Dingemans, A. E., Spinhoven, P., \& Furth, E. F. (2013). Treating eating disorders over the Internet: a systematic review and future research directions. International Journal of Eating Disorders, 46, 539-55. doi: 10.1002/eat.22135 
Andersson, G. (2016). Internet-Delivered Psychological Treatments. Annual Review of Clinical Psychology, 12(1), 157-179. http://doi.org/10.1146/annurev-clinpsy-021815093006

Andersson, G., Carlbring, P., Furmark, T., \& on behalf of the SOFIE Research Group. (2012). Therapist experience and knowledge acquisition in Internet-delivered CBT for social anxiety disorder: A randomized controlled trial. PloS ONE, 7(5), e37411. doi: 10.1371/journal.pone.0037411

American Psychiatric Association (2000). Diagnostic and statistical manual of mental disorders (4th ed.). Washington DC: American Psychiatric Press.

Bendelin, N., Hesser, H., Dahl, J., Carlbring, P., Zetterqvist Nelson, K., \& Andersson, G. (2011). Experiences of guided Internet-based cognitive-behavioural treatment for depression: A qualitative study. BMC Psychiatry, 11, 107. doi: 10.1186/1471-244X-11107

Berger, T., Boettcher, J., \& Caspar, F. (2014). Internet-based guided self-help for several anxiety disorders: A randomized controlled trial comparing a tailored with a standardized disorder-specific approach. Psychotherapy, 51, 207-219. doi: 10.1037/a0032527

Bergman Nordgren, L., Hedman, E., Etienne, J., Bodin J., Kadowaki, Å., Eriksson, S., Lindkvist, E., Andersson, G., \& Carlbring, P. (2014). Effectiveness and cost-effectiveness of individually tailored Internet-delivered cognitive behavior therapy for anxiety disorders in a primary care population: A randomized controlled trial. Behaviour Research and Therapy, 59, 1-11. doi: 10.1016/j.brat.2014.05.007

Carrard, I., Crépin, C., Rouget, P., Lam, T., Golay, A., \& Van der Linden, M. (2011). Randomised controlled trial of a guided self-help treatment on the Internet för binge eating disorder. Behaviour Research and Therapy, 49, 482-491. doi:10.1016/j.brat.2011.05.004 
Carter, J. C., \& Fairburn, C. G. (1998). Cognitive-behavioral self help for binge eating disorder: a controlled effectiveness study. Journal of Consulting and Clinical Psychology, 66, 616-623.

Cohen, J. (1988). Statistical power analysis for the behavioral sciences (2nd ed.). Hillsdale, NJ: Lawrence Earlbaum Associates.

Cooper, P. J., Taylor, M., Cooper, Z., \& Fairburn, C. G. (1987). The development and validation of the Body Shape Questionnaire. International Journal of Eating Disorders, 6, 807-812.

Crow, S. J., Agras,W. S., Halmi, K. A., Fairburn, C. G., Mitchell, J. E., \& Nyman, J. A. (2013). A Cost Effectiveness Analysis of Stepped Care Treatment for Bulimia Nervosa. International Journal of Eating Disorders, 46, 302-307. DOI: 10.1002/eat.22087

Davis, R., Olmsted, M., Rockert, W., Marques, T. \& Dolhanty, J. (1997). Group psychoeducation for bulimia nervosa with and without additional psychotherapy process sessions. International Journal of Eating Disorders, 22, 25-34.

Fairburn, C. G., \& Cooper, Z. (1993). The Eating Disorder Examination. (12 ${ }^{\text {th }}$ ed.). I C. G. Fairburn \& G. T. Wilson (Eds.) Binge eating: nature, assessment, and treatment. New York: Guilford Press.

Fairburn, C.G. (2008). Cognitive behavior therapy and eating disorders. New York: Guilford Press.

Fairburn, C. G., \& Beglin S. J. (2008). Eating Disorders Examination Questionnaire (EDE-Q 6.0). In C. G. Fairburn, Cognitive Behavior Therapy and Eating Disorders. New York: Guilford Press.

Fairburn C.G, Cooper Z., Doll H.A., O’Connor M.E., Bohn K., Hawker D.M, Wales J.A., \& Palmer R.L. (2009). Transdiagnostic Cognitive-Behavioral Therapy for Patients With 
Eating Disorders: A Two-Site Trial With 60-Week Follow-Up. American Journal of Psychiatry, 166, 311-319. doi: 10.1176/appi.ajp.2008.08040608

Fairburn, C. G., Cooper, Z., Doll, H. A., O'Connor, M. E., Palmer, R. L., \& Grave, R. D. (2013). Enhanced cognitive behaviour therapy for adults with anorexia nervosa: A UKItaly study. Behaviour Research and Therapy, 51, 2-8. doi:10.1016/j.brat.2012.09.010

Forman, E.M., Lillis, J., Butryn, M.L., Haynos. A.F. (2016). Mindfulness and Acceptance for Treating Eating Disorders and Weight Concerns Evidence-Based Interventions. Oakland: New Harbinger.

Freidberg, R., Viglione, D., Fidaleo, R. Celeste, B., Lovette, J., Street, G., Yerka, E., Bieraugel, M., Dumas, M., \& Beal, K. (1998). Measuring how we preach what we practice: Psychoeducational change in depressed inpatients. Journal of Rational-Emotive \& Cognitive-Behavior Therapy, 16, 45-59.

Frisch, M. B., Cornell, J., Villanueva, M., \& Retzlaff, P. J. (1992). Clinical Validation of the Quality of Life Inventory: A Measure of Life Satisfaction for Use in Treatment Planning and Outcome Assessment. Psychological Assessment, 4, 92-101. http://dx.doi.org/10.1037/1040-3590.4.1.92

Ghaderi (2006). Does individualization matter? A randomized trial of standardized (focused) versus individualized (broad) cognitive behavior therapy for bulimia nervosa. Behavior Research and Therapy, 44, 273-288. doi: 10.1016/j.brat.2005.02.004

Grilo, C. M., \& Masheb, R. M. (2005). A randomized controlled comparison of guided selfhelp cognitive behavioral therapy and behavioral weight loss for binge eating disorder. Behaviour and Therapy, 43, 1509-1525.

Hayes, S. C., Strosahl, K., \& Wilson, K. (1999). Acceptance and Commitment Therapy. An experiental approach to behavior change. New York: Guilford Press. 
Hansson, M., Chotai, J., Nordström, A., \& Bodlund, O. (2009). Comparison of two self-rating scales to detect depression: HADS and PHQ-9. British Journal of General Practice, 59, 283-288. doi:10.3399/bjgp09X454070

Harvey, A., Lee, J., Williams, J., Hollon, S., Walker, M., Thompson, M. \& Smith, R. (2014). Improving outcome of psychosocial treatments by enhancing memory and learning. Perspectives on Psychosocial Science, 6, 161-179. doi: 10.1177/1745691614521

Holmes E.A., Craske M.G.,Graybiel A.M. (2014). Psychological treatments: A call for mental-health science. Nature, 17, 287-9. doi: 10.1038/511287a.

Jacobson, N. S., \& Truax, P. (1991). Clinical significance: a statistical approach to defining meaningful change in psychotherapy research. Journal of Consulting and Clinical Psychology, 59, 12-19.

Johansson, R., Sjöberg, E., Sjögren, M., Johnsson, E., Carlbring, P., Andersson, T., Rousseau, A., \& Andersson, G. (2012). Tailored vs. standardized Internet-based cognitive behavior therapy for depression and comorbid symptoms: A randomized controlled trial. PLoS ONE, 7, e36905. doi: 10.1371/journal.pone.0036905

Kazdin, A.E. (2008). Evidence-Based Treatments and Delivery of Psychological Services: Shifting Our Emphases to Increase Impact. Psychological Services, 5, 201-215. doi: 10.1037/a0012573

Kroenke, K., Spitzer, R. L., \& Williams, J. B. W. (2001). The PHQ-9: Validity of a brief depression severity measure. Journal of General Internal Medicine, 16, 606613. doi: 10.1046/j.1525-1497.2001.016009606.x

Lillis J., Dahl J., Weineland S. (2014). The Diet Trap. Feed your psychological needs and end the weight loss struggle using acceptance and commitment therapy. New Harbinger Publisher. Oakland. 
Ljótsson, B., Lundin, C., Mitsell, K., Carlbring, P., Ramklint, M., \& Ghaderi, A. (2007). Remote treatment of bulimia nervosa and binge eating disorder: a randomized trial of Internet-assisted cognitive behavioural therapy. Behaviour Research and Therapy, 45, 649661. doi: 10.1016/j.brat.2006.06.010

Loeb, K. L., Wilson, G. T., Gilbert, J. S., \& Labouvie, E. (2000). Guided and unguided selfhelp for binge eating. Behaviour Research and Therapy, 38, 259-272.

Loucas, C.E., Fairburn, C.G., Whittington, C., Pennant, M.E., Stockton, S. \& Kendall, T. (2014). E-therapy in the treatment and prevention of eating disorders: A systematic review and meta-analysis. Behavior Research and Therapy, 5, 122-131. doi: 10.1016/j.brat.2014.09.011

Melioli T., Bauer S., Franko D.L., Moessner M., Ozer F., Chabrol H., \& Rodgers R.F. (2016). Reducing eating disorder symptoms and risk factors using the internet: A meta-analytic review. International Journal of Eating Disorders, 49, 19-31. doi: 10.1002/eat.22477.

Sanderson, W. \& Bruce, T. (2007). Causes and management of treatment-resistance panic disorder and agoraphobia: A survey of expert therapists. Cognitive and Behavioral Practice, 14, 26-35. doi: 10.1016/j.cbpra.2006.04.020

Schlegl, S., Bürger, C., Schmidt, L., Herbs,t N., \& Voderholzer, .U. (2015). The Potential of Technology-Based Psychological Interventions for Anorexia and Bulimia Nervosa: A Systematic Review and Recommendations for Future Research. Journal of Medical Internet Research, 17, e85. doi: 10.2196/jmir.3554

Schibbye, P., Ghaderi, A., Ljótsson, B., Hedman, E., Lindefors, N., Rück, C., \& Kaldo, V. (2014). Using Early Change to Predict Outcome in Cognitive Behaviour Therapy: Exploring Timeframe, Calculation Method, and Differences of Disorder-Specific versus General Measures. PLOS ONE, 24, e100614. doi: 10.1371/journal.pone.0100614. 
Scogin, F., Jamison, C., Floyd, M., Chaplin, W.F. (1998) Measuring learning in depression treatment: A cognitive bibliotherapy test. Cognitive Therapy and Research, 22, 475482.

Sheehan, D. V., Lecrubier, Y., Sheehan, K. H., Amorim, P., Janavs, J., Weiller, E., Hergueta, T., Baker, R., \& Dunbar, G. C. (1998). The mini-international neuropsychiatric interview (M.I.N.I.): The development and validation of a structured diagnostic psychiatric interview for DSM-IV and ICD-10. Journal of Clinical Psychiatry, 59, 22-33.

Spitzer, R. L., Kroenke, K., Williams, J. W., \& Löwe, B. (2006). A brief measure for assessing generalized anxiety disorder: The GAD-7. Archives Of Internal Medicine, 166, 1092-1097. doi:10.1001/archinte.166.10.1092

Tatham, M., Dodd, E.A., \& Waller, G. (2015). The effect of pre-treatment psychoeducation on eating disorder pathology among patients with anorexia nervosa and bulimia nervosa. Advances in Eating Disorders, 4, 167-175. doi: 10.1080/21662630.2016.1172975

Tursi, M., Werne Baes, C., Camacho, F., Tofoli, S. \& Juruena, M. (2013). Effectiveness of psychoeducation for depression: A systematic review. Australian \& New Zealand Journal of Psychiatry. 47, 1019-1031. doi: 10.1177/0004867413491154

Wallace, L.M. \& von Ranson, K.M. (2011). Treatment manuals: use in the treatment of bulimia nervosa. Behavior Research and Therapy, 49, 815-820. doi: 10.1016/j.brat.2011.09.002

Watson, H. J., Allen, K., Fursland, A., Byrne, S. M., \& Nathan, P. R. (2012). Does enhanced cognitive behavior therapy for eating disorders improve quality of life? European Eating Disorders Review, 20, 393-399. doi: 10.1002/erv.2186

Welch, E., Birgegård, A., Parling, T., \& Ghaderi, A. (2011). Eating disorder examination questionnaire and clinical impairment assessment questionnaire: General population 
and clinical norms for young adult women in Sweden. Behaviour Research and Therapy, 49, 85-91. doi:10.1016/j.brat.2010.10.010

Welch, E., Lagerström, M., \& Ghaderi, A. (2012). Body Shape Questionnaire: Psychometric properties of the short version (BSQ-8C) and norms from the general Swedish population. Body Image, 9, 547-550. doi: 10.1016/j.bodyim.2012.04.009

Wilson, G. T., Fairburn, C. G., Agras, W. S., Walsh, B. T., \& Kraemer, H. (2002). Cognitive behavior therapy for bulimia nervosa: time course and mechanisms of change. Journal of consulting and clinical psychology, 70, 267-274. doi: 10.1037/0022-006X.70.2.267

Wilson G.T., Grilo, C.M., \& Vitousek, K.M (2007). Psychological treatment of eating disorders. American Psychologist, 62, 199-216. doi: 10.1037/0003-066X.62.3.199

Zerwas S.C., Watson, H.J., Hofmeier, S.M., Levine, M.D., Hame,r R.M., Crosby, R.D., Runfola, C.D., Pea,t C.M., Shapiro, J.R., Zimmer, B., Moessner, M., Kordy H., Marcus M.D., Bulik, C.M (2017). A Randomized Controlled Trial of Online Chat and Face-toFace Group Therapy for Bulimia Nervosa. Psychotherapy and Psychosomatics, 86,4753. doi:10.1159/000449025 


\section{Highlights}

- The efficacy of tailored and ACT-influenced cognitive behavioral internet treatment for eating disorder psychopathology was investigated.

- The relation between knowledge acquisition and outcome was explored.

- The intervention showed promising effect for people with eating disorder psychopathology.

- Although treatment helped patients acquire knowledge about eating disorders and their management, we failed to find a significant relationship between knowledge acquisition and outcome 


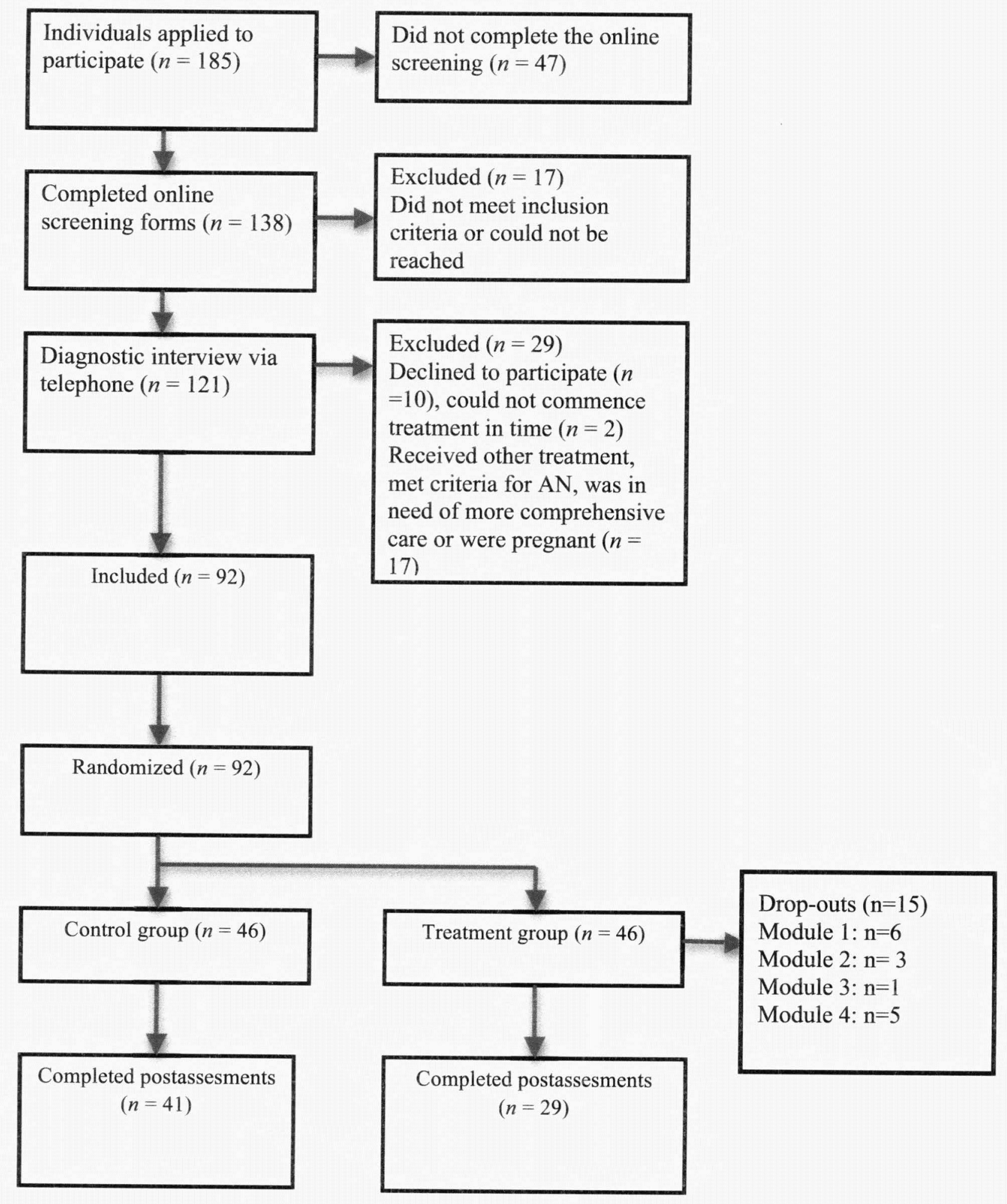

Figure 1. Flowchart describing inclusion and exclusion of participants. 


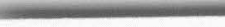

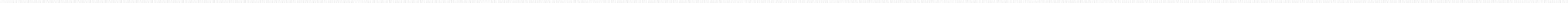




\section{Table 1.}

Characteristics of the study sample, as well as the control versus the treatment group, and statistical analyses comparing the intervention and the control group

\begin{tabular}{|c|c|c|c|c|}
\hline & $\begin{array}{l}\text { Total } \\
(N=92)\end{array}$ & $\begin{array}{l}\text { Control } \\
(n=46)\end{array}$ & $\begin{array}{l}\text { Treatment } \\
(n=46)\end{array}$ & $\begin{array}{l}\text { Statistical } \\
\text { analysis }\end{array}$ \\
\hline Gender & & & & \multirow{3}{*}{$\begin{array}{l}\text { Fisher's Exact } \\
\text { Test: } p=.24\end{array}$} \\
\hline Women & $89(96.7 \%)$ & $46(100 \%)$ & $43(93.5 \%)$ & \\
\hline Men & $3(3.3 \%)$ & 0 & $3(6.5 \%)$ & \\
\hline BMI & & & & \multirow{3}{*}{$\begin{array}{l}t(90)=-1.41 \\
p=.16\end{array}$} \\
\hline Mean $(S D)$ & $25.45(5.91)$ & $26.31(6.36)$ & $24.59(5.38)$ & \\
\hline Min-Max & $17.79-41.59$ & 17.79- 41.59 & 18.40- 39.67 & \\
\hline Age & & & & \multirow{3}{*}{$\begin{array}{l}t(90)=-0.23 \\
p=.82\end{array}$} \\
\hline Mean $(S D)$ & $29.14(9.69)$ & $28.91(9.86)$ & 29.37 (9.63) & \\
\hline Min-Max & $18-64$ & $19-61$ & $18-64$ & \\
\hline Civil status & & & & \multirow{5}{*}{$\begin{array}{l}X^{2}(\mathrm{df}=3 \\
\mathrm{N}=92)=3.92 \\
p=.27 \#\end{array}$} \\
\hline Single & 36 (39.1\%) & $16(34.8 \%)$ & $20(43.5 \%)$ & \\
\hline Married/ Partner & $53(57.6 \%)$ & $29(63 \%)$ & $24(52.2 \%)$ & \\
\hline Divorced/widow/widowed & $1(1.1 \%)$ & $1(2.2 \%)$ & 0 & \\
\hline Other & $2(2.2 \%)$ & 0 & $2(4.3 \%)$ & \\
\hline $\begin{array}{l}\text { Highest completed } \\
\text { educational level }\end{array}$ & & & & \multirow{4}{*}{$\begin{array}{l}X^{2}(\mathrm{df}=2 \\
\mathrm{N}=92)=1.25 \\
p=.54\end{array}$} \\
\hline $\begin{array}{l}\text { Nine-year compulsory } \\
\text { school }\end{array}$ & $3(3.3 \%)$ & $1(2.2 \%)$ & $2(4.3 \%)$ & \\
\hline $\begin{array}{l}\text { Senior high } \\
\text { school/secondary school }\end{array}$ & 45 (48.9 \%) & 25 (54.3 \%) & $20(43.5 \%)$ & \\
\hline University & $44(47.8 \%)$ & $20(43.5 \%)$ & $24(52.2 \%)$ & \\
\hline $\begin{array}{l}\text { Previous psychological } \\
\text { treatment }\end{array}$ & 45 (48.9 \%) & 27 (58.7 \%) & 18 (39.1%) & $\begin{array}{l}X^{2}(\mathrm{df}=1 \\
\mathrm{N}=92)=3.52 \\
p=.06\end{array}$ \\
\hline
\end{tabular}


Table 2.

Clinical characteristics of the total sample, as well as the control versus the treatment group

\begin{tabular}{llll} 
M (SD) & Total $(\boldsymbol{N}=\mathbf{9 2})$ & Control $(\boldsymbol{n}=\mathbf{4 6})$ & Treatment $(\boldsymbol{n}=\mathbf{4 6})$ \\
\hline $\begin{array}{l}\text { Years of eating } \\
\text { difficulties }\end{array}$ & $13.02(10.83)$ & $13.70(10.94)$ & $12.34(10.80)$ \\
Min-max & $1-60$ & $1.5-46$ & $1-60$ \\
& & & \\
$\begin{array}{l}\text { Frequency OBE } \\
\text { Min-max }\end{array}$ & $9.92(9.75)$ & $9.00(8.93)$ & $10.85(10.53)$ \\
& $0-40$ & $0-38$ & $0-40$ \\
$\begin{array}{l}\text { Frequency } \\
\text { compensatory }\end{array}$ & & & \\
behaviour & & & \\
$\begin{array}{l}\text { Purging } \\
\text { Min-max }\end{array}$ & $2.37(6.33)$ & $1.65(4.3)$ & $3.09(7.83)$ \\
$\begin{array}{l}\text { Laxative } \\
\text { Min-max }\end{array}$ & $0-40$ & $0-20$ & $0-40$ \\
& $0.80(3.34)$ & $0.7(2.23)$ & $0.91(4.19)$ \\
Compulsive training & $7.04(8.14)$ & $0-12$ & \\
Min-max & $0-28$ & $8.59(8.89)$ & $5.50(7.11)$ \\
& & $0-28$ & $0-25$ \\
$\begin{array}{l}\text { Age first dieting } \\
\text { Min-max }\end{array}$ & $15.98(4.10)$ & $15.09(2.84)$ & $16.87(4.93)$ \\
& $8-35$ & $8-21$ & $10-35$ \\
Weight loss surgery & & & \\
N (\%) & $8(8.7 \%)$ & $5(10.9 \%)$ & $3(6.5 \%)$ \\
\hline
\end{tabular}

OBE = Objective bulimic episode 
Table 3.

Diagnostic distribution (participants can have more than one disorder)

\begin{tabular}{|c|c|c|c|}
\hline & Total $(N=92)$ & Control $(n=46)$ & Treatment $(n=46)$ \\
\hline \multicolumn{4}{|l|}{ Eating disorder (\%) } \\
\hline $\mathrm{BN}$ & 36 (39.1\%) & $18(39.1 \%)$ & 18 (39.1\%) \\
\hline EDNOS & $56(60.9 \%)$ & $28(60.9 \%)$ & $28(60.9 \%)$ \\
\hline \multicolumn{4}{|l|}{ Depressive episode } \\
\hline Current & $57(62.0 \%)$ & $27(58.7 \%)$ & $30(65.2 \%)$ \\
\hline \multicolumn{4}{|l|}{ Previous } \\
\hline $\begin{array}{l}\text { Manic/hypomanic } \\
\text { episode (\%) }\end{array}$ & $2(2.2 \%)$ & $2(4.3 \%)$ & 0 \\
\hline Current & $5(5.4 \%)$ & $4(8.7 \%)$ & $1(2.2 \%)$ \\
\hline \multicolumn{4}{|l|}{ Previous } \\
\hline Bipolar 1 (\%) & $1(1.1 \%)$ & 0 & $1(2.2 \%)$ \\
\hline Bipolar 2 (\%) & $3(3.3 \%)$ & $3(6.5 \%)$ & 0 \\
\hline $\begin{array}{l}\text { Bipolar unspecified } \\
(\%)\end{array}$ & 0 & 0 & 0 \\
\hline PTSD (\%) & $1(1.1 \%)$ & $1(2.2 \%)$ & 0 \\
\hline $\begin{array}{l}\text { Alcohol dependence } \\
(\%)\end{array}$ & $7(7.6 \%)$ & $3(6.5 \%)$ & $4(8.7 \%)$ \\
\hline Alcohol abuse (\%) & $3(3.3 \%)$ & $2(4.3 \%)$ & $1(2.2 \%)$ \\
\hline Drug dependence (\%) & $2(2.2 \%)$ & $1(2.2 \%)$ & $1(2.2 \%)$ \\
\hline Drug abuse (\%) & 0 & 0 & 0 \\
\hline GAD (\%) & $32(34.8 \%)$ & $14(30.4 \%)$ & 18 (39.1\%) \\
\hline \multicolumn{4}{|l|}{ Social phobia (\%) } \\
\hline Generalized & $7(7.6 \%)$ & $4(8.7 \%)$ & $3(6.5 \%)$ \\
\hline Non-generalized & $7(7.6 \%)$ & $1(2.2 \%)$ & $6(13.0 \%)$ \\
\hline $\begin{array}{l}\text { Antisocial personality } \\
\text { disorder (\%) }\end{array}$ & $1(1.1 \%)$ & $1(2.2 \%)$ & 0 \\
\hline OCD (\%) & $10(10.9 \%)$ & $5(10.9 \%)$ & $5(10.9 \%)$ \\
\hline
\end{tabular}


Panic disorder (\%)

Current

Previous

Agoraphobia (\%)

More than one disorder
$6(6.5 \%)$

$11(12.0 \%)$

$10(10.9 \%)$

$21(77.2 \%)$
$3(6.5 \%)$

$5(10.9 \%)$

$4(8.7 \%)$

$34(73.9 \%)$
$3(6.5 \%)$

$6(13.0 \%)$

$6(13.0 \%)$

37 (80.4\%)

$P T S D=$ Posttraumatic stress disorder $G A D=$ Generalized anxiety disorder $O C D=$ Obsessive compulsive disorder 



\section{Table 4.}

Treatment modules and their core components.

\begin{tabular}{|l|l|}
\hline $\begin{array}{l}\text { DISORDERED EATING } \\
\text { (module 1-4) }\end{array}$ & DESCRIPTION \\
\hline Module 1- Starting well & $\begin{array}{l}\text { The treatment rationale was presented, } \\
\text { symptoms and the effectiveness of previous } \\
\text { strategies was investigated. Treatment goals } \\
\text { were established. }\end{array}$ \\
\hline $\begin{array}{l}\text { Module 2 - change your eating habits, create } \\
\text { new opportunities }\end{array}$ & $\begin{array}{l}\text { Functional analysis was presented and a } \\
\text { focus on establishing healthy eating habits } \\
\text { was discussed. Throughout treatment } \\
\text { participants were taught a variety of } \\
\text { techniques aimed at shifting the focus of } \\
\text { control over inner experiences and increasing } \\
\text { the willingness to experience them while } \\
\text { engaging in healthy and valued behaviors. }\end{array}$ \\
\hline Module 3 - reduced control, greater freedom & $\begin{array}{l}\text { Investigation of control and avoidance } \\
\text { behaviors, perfectionism and the feeling of } \\
\text { fatness. Alternative behaviors were } \\
\text { introduced and commitment to new } \\
\text { behavioral patterns was stressed.. }\end{array}$ \\
\hline $\begin{array}{l}\text { Module 4 - acceptance, finding new ways in } \\
\text { life }\end{array}$ & $\begin{array}{l}\text { Strategies for handling negative inner } \\
\text { experiences such as mindfulness, defusion } \\
\text { and acceptance were introduced. }\end{array}$ \\
\hline $\begin{array}{l}\text { TAILORED TREATMENT } \\
\text { (module 4-7) }\end{array}$ & $\begin{array}{l}\text { Overarching components and structure in all the modules: } \\
\text { presenting a theme for each week. The structure of the modules included following up } \\
\text { homework from the previous session, psychoeducation about the theme of the week, } \\
\text { instructions, and new home exercises. Participants were asked to keep a food diary. The first } \\
\text { four modules of the treatment encompassed the core psychopathology of eating disorders, } \\
\text { and the remaining four modules combined interventions directly focusing on eating disorders, } \\
\text { with tailored modules based on the participant's individual difficulties. }\end{array}$ \\
\hline Living with obesity and self-stigma & $\begin{array}{l}\text { Self-stigma and emotional eating was } \\
\text { investigated and values work presented. } \\
\text { Concrete behavior change in a healthy } \\
\text { direction was established and hindrances } \\
\text { addressed. }\end{array}$ \\
\hline
\end{tabular}




\begin{tabular}{|l|l|}
\hline Behavioral activation, when feeling down & $\begin{array}{l}\text { Psychoeducation on depression and patterns } \\
\text { of avoidance was addressed. Values work } \\
\text { and behavioral activation were the main } \\
\text { strategies. }\end{array}$ \\
\hline Freeing yourself from worries and anxiety & $\begin{array}{l}\text { Psychoeducation on anxiety and avoidance } \\
\text { was presented. Strategies, such as anxiety- } \\
\text { free-zones and alternative behaviors, as well } \\
\text { as values work and goals were introduced. }\end{array}$ \\
\hline Emotional turmoil and emotional regulation & $\begin{array}{l}\text { Emotion regulations skills were presented. } \\
\text { Psychoeducation on emotions and strategies } \\
\text { such as identify emotions, acceptance and } \\
\text { mindfulness were introduced. }\end{array}$ \\
\hline Last module & $\begin{array}{l}\text { The focus was on summarizing the treatment } \\
\text { gains, strategies to maintain them and relapse } \\
\text { prevention.. }\end{array}$ \\
\hline
\end{tabular}



Table 5.

Treatment outcome variables for all randomized participants (Intent- To-Treat Analysis)

\begin{tabular}{|c|c|c|c|c|c|c|}
\hline \multirow{2}{*}{$\begin{array}{l}\text { Measure and group } \\
\text { Treatment }(n=46) \\
\text { Control }(n=46)\end{array}$} & \multirow{2}{*}{$\begin{array}{l}\text { Pre } \\
M(S D)\end{array}$} & \multirow{2}{*}{$\begin{array}{l}\text { Post } \\
M(S D)\end{array}$} & \multicolumn{2}{|c|}{$\begin{array}{l}\text { Within group, } \\
\text { dependent } t \text {-test }\end{array}$} & \multicolumn{2}{|c|}{$\begin{array}{l}\text { Between group, } \\
\text { ANCOVA }\end{array}$} \\
\hline & & & $t(45), t(45)$ & $d$ & $F(1,89)$ & $d(C I)$ \\
\hline Global score (EDE-Q) & & & & & $-3.51 * * *$ & $\begin{array}{l}0.54 \\
(-1.03,-0.22)\end{array}$ \\
\hline Treatment & $3.63(0.91)$ & $2.84(1.68)$ & $5.61^{* * *}$ & 0.83 & & \\
\hline Control & $3.87(1.00)$ & $3.62(1.15)$ & 1.8 (ns) & & & \\
\hline Diet restraint (EDE-Q) & & & & & $-3.67 * * *$ & $\begin{array}{l}0.64 \\
(-.25,-0.23)\end{array}$ \\
\hline Treatment & $2.81(1.17)$ & $2.01(2.12)$ & $4.01 * * *$ & 0.59 & & \\
\hline Control & $3.20(1.45)$ & $3.16(1.44)$ & $-0.16(\mathrm{~ns})$ & & & \\
\hline Eating concern (EDE-Q) & & & & & $-2.36^{*}$ & $\begin{array}{l}0.35 \\
(-1.07,0.10)\end{array}$ \\
\hline Treatment & $3.31(1.37)$ & $2.48(2.51)$ & $3.84 * * *$ & 0.57 & & \\
\hline Control & $3.39(1.16)$ & $3.20(1.56)$ & 1.11 (ns) & & & \\
\hline Weight concern (EDE-Q) & & & & & $-2.41^{*}$ & $\begin{array}{l}0.42 \\
(-0.96,-0.03)\end{array}$ \\
\hline Treatment & 3.87 (1.19) & $3.05(1.88)$ & $4.50 * * *$ & 0.66 & & \\
\hline Control & $4.17(1.15)$ & $3.73(1.35)$ & $2.55^{*}$ & 0.38 & & \\
\hline Shape concern (EDE-Q) & & & & & $-2.44^{*}$ & $\begin{array}{l}0.35 \\
(-0.90,0.05)\end{array}$ \\
\hline Treatment & $4.52(1.00)$ & $3.8(1.92)$ & $4.98 * * *$ & 0.73 & & \\
\hline Control & $4.73(1.22)$ & $4.38(1.39)$ & $2.64 * *$ & 0.39 & & \\
\hline BSQ & & & & & $-2.52 *$ & $\begin{array}{l}0.48 \\
(-4.41,2.05)\end{array}$ \\
\hline Treatment & $33.77(8.04)$ & 28.32(13.59) & $3.54 * *$ & 0.52 & & \\
\hline Control & $36.00(6.44)$ & $33.84(8.79)$ & $2.41 *$ & 0.36 & & \\
\hline SWLS & & & & & $0.14(\mathrm{~ns})$ & $\begin{array}{l}0.02 \\
(-2.27,1.52)\end{array}$ \\
\hline Treatment & $14.43(5.46)$ & $14.58(7.91)$ & $-1.77(\mathrm{~ns})$ & & & \\
\hline Control & $13.17(4.49)$ & $14.47(5.20)$ & $-2.27^{*}$ & 0.33 & & \\
\hline QOLI & & & & & -0.78 (ns) & \\
\hline Treatment & $0.64(1.55)$ & $1.11(2.11)$ & $-2.34 *$ & & & $\begin{array}{l}0.14 \\
(-0.75,0.27)\end{array}$ \\
\hline Control & 1.07 (1.59) & $1.36(1.42)$ & $-1.85(\mathrm{~ns})$ & 0.35 & & \\
\hline PHQ-9 & & & & & 1.57 (ns) & $\begin{array}{l}0.21 \\
(-2.57,1.48)\end{array}$ \\
\hline Treatment & $11.83(5.31)$ & $8.25(8.18)$ & $4.74 * * *$ & 0.70 & & \\
\hline Control & $12.45(4.31)$ & $9.73(5.84)$ & $3.23 * * *$ & 0.48 & & \\
\hline
\end{tabular}


GAD-7

-0.84 (ns) $\quad 0.21$

Treatment $\quad 7.37(4.94) \quad 6.44(6.76) \quad 1.21$ (ns)

$\begin{array}{llll}\text { Control } & 9.02(5.18) & 7.65(4.69) & 1.18 \text { (ns) }\end{array}$

${ }^{*} p<.05,{ }^{* *} p<.01, * * * p<.001$ 


\section{Table 6 - online supplementary document}

Treatment outcomes for all randomized participants (Intent- To-Treat Analysis) using repeated measure ANOVA

\begin{tabular}{|l|l|l|l|}
\hline Outcome variables ${ }^{1}$ & Time effect & Group effect & Interaction effect \\
\hline Global score (EDE-Q) & $\mathrm{F}(1,90)=14.11, \mathrm{p}<.001,{ }_{\mathrm{p}} \eta^{2}=.27$ & $\mathrm{~F}(1,90)=4.67, \mathrm{p}=.033,{ }_{\mathrm{p}} \eta^{2}=.05$ & $\mathrm{~F}(1,90)=4.77, \mathrm{p}<.001,{ }_{\mathrm{p}} \eta^{2}=.11$ \\
\hline Diet restraint (EDE-Q) & $\mathrm{F}(1,90)=11.93, \mathrm{p}<.001,{ }_{\mathrm{p}} \eta^{2}=.12$ & $\mathrm{~F}(1,90)=9.71, \mathrm{p}=.002,{ }_{\mathrm{p}} \eta^{2}=.10$ & $\mathrm{~F}(1,90)=9.14, \mathrm{p}=.003,{ }_{\mathrm{p}} \eta^{2}=.09$ \\
\hline Eating concern (EDE-Q) & $\mathrm{F}(1,90)=15.24, \mathrm{p}<.001,{ }_{\mathrm{p}} \eta^{2}=.15$ & $\mathrm{~F}(1,90)=2.26, \mathrm{p}=.137,{ }_{\mathrm{p}} \eta^{2}=.02$ & $\mathrm{~F}(1,90)=7.39, \mathrm{p}=.008,{ }_{\mathrm{p}} \eta^{2}=.08$ \\
\hline Weight concern (EDE-Q) & $\mathrm{F}(1,90)=29.14, \mathrm{p}<.001,{ }_{\mathrm{p}} \eta^{2}=.25$ & $\mathrm{~F}(1,90)=4.85, \mathrm{p}=.030,{ }_{\mathrm{p}} \eta^{2}=.05$ & $\mathrm{~F}(1,90)=4.33, \mathrm{p}=.040,{ }_{\mathrm{p}} \eta^{2}=.05$ \\
\hline Shape concern (EDE-Q) & $\mathrm{F}(1,90)=32.89, \mathrm{p}<.001,{ }_{\mathrm{p}} \eta^{2}=.27$ & $\mathrm{~F}(1,90)=1.99, \mathrm{p}=.162,{ }_{\mathrm{p}} \eta^{2}=.02$ & $\mathrm{~F}(1,90)=6.08, \mathrm{p}=.016,{ }_{\mathrm{p}} \eta^{2}=.06$ \\
\hline BSQ & $\mathrm{F}(1,90)=36.99, \mathrm{p}<.001,{ }_{\mathrm{p}} \eta^{2}=.29$ & $\mathrm{~F}(1,90)=6.16, \mathrm{p}=.015,{ }_{\mathrm{p}} \eta^{2}=.06$ & $\mathrm{~F}(1,90)=14.43, \mathrm{p}<.001,{ }_{\mathrm{p}} \eta^{2}=.14$ \\
\hline SWLS & $\mathrm{F}(1,90)=7.89, \mathrm{p}=.006,{ }_{\mathrm{p}} \eta^{2}=.08$ & $\mathrm{~F}(1,90)=6.16, \mathrm{p}=.015,{ }_{\mathrm{p}} \eta^{2}=.06$ & $\mathrm{~F}(1,90)=0.003, \mathrm{p}=.957,{ }_{\mathrm{p}} \eta^{2}=.00$ \\
\hline QOLI & $\mathrm{F}(1,90)=7.92, \mathrm{p}=.006,{ }_{\mathrm{p}} \eta^{2}=.08$ & $\mathrm{~F}(1,90)=1.21, \mathrm{p}=.27,{ }_{\mathrm{p}} \eta^{2}=.01$ & $\mathrm{~F}(1,90)=0.79, \mathrm{p}=.377,{ }_{\mathrm{p}} \eta^{2}=.01$ \\
\hline PHQ-9 & $\mathrm{F}(1,90)=29.06, \mathrm{p}<.001,{ }_{\mathrm{p}} \eta^{2}=.24$ & $\mathrm{~F}(1,90)=0.76, \mathrm{p}=.385,{ }_{\mathrm{p}} \eta^{2}=.01$ & $\mathrm{~F}(1,90)=4.88, \mathrm{p}=.30,{ }_{\mathrm{p}} \eta^{2}=.05$ \\
\hline GAD-7 & $\mathrm{F}(1,90)=2.62, \mathrm{p}=.109,{ }_{\mathrm{p}} \eta^{2}=.03$ & $\mathrm{~F}(1,90)=1.76, \mathrm{p}=.188,{ }_{\mathrm{p}} \eta^{2}=.02$ & $\mathrm{~F}(1,90)=0.03, \mathrm{p}=.871,{ }_{\mathrm{p}} \eta^{2}=.00$ \\
\hline
\end{tabular}

1 EDE-Q=Eating Disorders Examination Questionnaire, BSQ= Body Shape Questionnaire, SWLS=Satisfaction with Life Scale, QOLI=Quality of Life Inventory, PHQ-9= Patient Health Questionnaire-9, GAD-7= Generalized Anxiety Disorder-7 
Table 7 - online supplementary document

Treatment outcome variables for completers (complete-cases analysis)

\begin{tabular}{|c|c|c|c|c|c|c|}
\hline \multirow{2}{*}{$\begin{array}{l}\text { Measure and group } \\
\text { Treatment }(n=30) \\
\text { Control }(n=42) \\
\end{array}$} & \multirow{2}{*}{$\begin{array}{l}\text { Pre } \\
M(S D)\end{array}$} & \multirow{2}{*}{$\begin{array}{l}\text { Post } \\
M(S D)\end{array}$} & \multicolumn{2}{|c|}{$\begin{array}{l}\text { Within group } \\
\text { dependent } t \text {-test }\end{array}$} & \multicolumn{2}{|c|}{$\begin{array}{l}\text { Between group } \\
\text { ANCOVA }\end{array}$} \\
\hline & & & $t(29), t(41)$ & $d$ & $F(1,69)$ & $d(C I)$ \\
\hline \multicolumn{7}{|l|}{$\begin{array}{l}\text { Global score } \\
\text { (EDE-Q) }\end{array}$} \\
\hline Treatment & $3.63(0.91)$ & $2.57(1.19)$ & $7.10^{* * *}$ & 1.3 & 21.98 & 0.98 \\
\hline Control & $3.87(1.00)$ & $3.68(1.10)$ & 1.51 (ns) & & & $\begin{array}{l}(-1.41, \\
-0.66)\end{array}$ \\
\hline \multicolumn{7}{|l|}{ Diet restraint (EDE- } \\
\hline $\begin{array}{l}\text { Q) } \\
\text { Treatment } \\
\text { Control }\end{array}$ & $\begin{array}{l}2.81(1.17) \\
3.20(1.45)\end{array}$ & $\begin{array}{l}1.60(1.25) \\
3.26(1.33)\end{array}$ & $\begin{array}{l}7.27 * * * \\
-.28(\mathrm{~ns})\end{array}$ & 1.33 & 32.45 & $\begin{array}{l}1.28 \\
(-1.74, \\
-0.90)\end{array}$ \\
\hline \multicolumn{7}{|l|}{$\begin{array}{l}\text { Eating concern } \\
\text { (EDE-Q) }\end{array}$} \\
\hline Treatment & 3.31 (1.37) & $2.29(1.51)$ & $4.38 * * *$ & 0.8 & 10.32 & 0.64 \\
\hline Control & $3.39(1.16)$ & $3.25(1.50)$ & $.82(\mathrm{~ns})$ & & & $\begin{array}{l}(-1.19, \\
-0.19)\end{array}$ \\
\hline \multicolumn{7}{|l|}{$\begin{array}{l}\text { Weight concern } \\
\text { (EDE-Q) }\end{array}$} \\
\hline Treatment & 3.87 (1.19) & $2.86(1.49)$ & $5.04 * * *$ & 0.92 & 8.90 & 0.71 \\
\hline Control & $4.17(1.15)$ & $3.80(1.18)$ & $2.48^{*}$ & 0.38 & & $\begin{array}{l}(-1.26, \\
-0.37)\end{array}$ \\
\hline \multicolumn{7}{|l|}{$\begin{array}{l}\text { Shape concern } \\
\text { (EDE-Q) }\end{array}$} \\
\hline Treatment & $4.52(1.00)$ & $3.52(1.44)$ & $5.06 * * *$ & 0.92 & 10.16 & 0.66 \\
\hline Control & $4.73(1.22)$ & $4.43(1.34)$ & $2.29 *$ & 0.35 & & $\begin{array}{l}(-1.18, \\
0,26)\end{array}$ \\
\hline \multicolumn{7}{|l|}{ BSQ } \\
\hline Treatment & 33.77 (8.04) & 26.60 (8.94) & $5.35 * * *$ & 0.98 & 19.45 & 0.97 \\
\hline Control & $36.00(6.44)$ & $34.40(7.35)$ & $2.44^{*}$ & 0.38 & & $\begin{array}{l}(-4.18, \\
1,24)\end{array}$ \\
\hline \multicolumn{7}{|l|}{ QOLI } \\
\hline Treatment & $0.64(1.55)$ & 1.15 (1.47) & $-2,04$ (ns) & & 0.07 (ns) & 0.13 \\
\hline Control & 1.07 (1.59) & $1.33(1.30)$ & -1.37 (ns) & & & $\begin{array}{l}(-0.66 \text {, } \\
0.26)\end{array}$ \\
\hline \multicolumn{7}{|l|}{ PHQ-9 } \\
\hline Treatment & $11.83(5.31)$ & $7.13(4.82)$ & $4.87 * * *$ & 0.89 & 4.34 & 0.49 \\
\hline Control & $12.45(4.31)$ & $9.93(6.22)$ & $3.372 * *$ & 0.52 & & $\begin{array}{l}(-2.22, \\
1.38)\end{array}$ \\
\hline \multicolumn{7}{|l|}{ GAD-7 } \\
\hline Treatment & 7.37 (4.94) & $5.73(4.31)$ & 1.62 (ns) & & 1.68 (ns) & 0.43 \\
\hline Control & $9.02(5.18)$ & $7.62(4.61)$ & $1.8(\mathrm{~ns})$ & & & $\begin{array}{l}(-1.97, \\
0.97)\end{array}$ \\
\hline
\end{tabular}

${ }^{*} p<.05,{ }^{* *} p<.01,{ }^{* * *} p<.001$ 